\title{
In-situ preparation of a highly accessible Pt/CNF catalytic layer on metallic microchannel reactors. Application to the SELOX reaction.
}

Adrián Ramírez ${ }^{1}$, Víctor Sebastián ${ }^{1,2}$, Reyes Mallada*1,2, Jesús Santamaría ${ }^{1,2}$, Antonio Monzón*1

${ }^{1}$ Institute of Nanoscience of Aragon, INA. Chemical and Environmental Engineering Department. University of Zaragoza. C/Mariano Esquillor s/n, 50018 Zaragoza. Spain. ${ }^{2} N e t w o r k i n g$ Research Center on Bioengineering, Biomaterials and Nanomedicine, CIBER-BBN, 28029 Madrid, Spain.

*Co-corresponding authors: rmallada@unizar.es, amonzon@unizar.es

Keywords: Microreactor, carbon nanofibers, CO SELOX, selective oxidation, platinum

\begin{abstract}
A general method to prepare a catalytic coating on the surface of stainless steel microreactors has been developed. The catalytic support consists of a layer of randomly oriented, highly accessible carbon nanofibers (CNFs), directly grown on the surface of the channels by chemical vapor deposition (CVD) of ethanol. These CNFs are functionalized to acquire a positive charge before a solution containing metallic nanoparticles $(\mathrm{Pt})$ is flown through the channels. The nanoparticles adhere to the surface of the CNFs thanks to electrostatic interactions. This process is carried out in-situ and the method can be easily adapted to larger scale production. These catalyst-coated microchannel reactors have been tested in the selective oxidation (SELOX) of CO in the presence of $\mathrm{H}_{2}$. The results were compared to those obtained in a conventional fixed bed reactor packed with Pt/CNTs. The microreactor clearly outperformed the fixed bed reactor at the same space velocity $\left(\mathrm{WSHV}=2220 \mathrm{l} / \mathrm{h} \mathrm{g}_{\mathrm{Pt}}\right)$,), achieving total $\mathrm{CO}$ conversion at temperatures $50{ }^{\circ} \mathrm{C}$ lower.
\end{abstract}

Keywords: Microreactor, Pt/CNF catalytic layer, SELOX, PROX 


\section{Introduction}

Microstructured reactors represent a key technology in the increasingly important area of mobile and decentralized energy production, where they are used in the purification of hydrogen streams for proton exchange fuel cells (PEFC) [1]. One of the bottlenecks in the implementation of microreactors for this application is the lack of scalable methods for the mass production of catalyst-coated channels. The methods used to deposit catalytic washcoatings in ceramic and metallic monoliths for automotive applications are being adapted for channels in stainless steel reactors, where the main challenges refer to improving adhesion and optimizing the distribution of the active sites in the catalyst layer [2, 3]. Other methods, different from washcoating, have been studied and reviewed by Meille et al. [4]. These methods include sol-gel techniques, and synthesis of zeolitic and carbon-based supports deposition on different structures[5]. In the case of metal supported catalysts, the deposition of the metal phase takes place in a second stage (after deposition of the support layer) and is usually accomplished by conventional techniques such as impregnation, precipitation and ion exchange.

The selective oxidation of CO, SELOX, it is a necessary step since the reformate stream fed to the PEFC should contain less than 100 ppm of CO, to avoid poisoning of the electrodes. The use of microreactors for SELOX has been recently reviewed by Kolb [1]. The most promising results include the use of bimetallic catalysts such as Pt/Rh (2.5\%wt.) [6] and Pt (1\%wt.)/Co(2 \%wt.) [7] on conventional $\mathrm{Al}_{2} \mathrm{O}_{3}$ support, washcoated on the microreactor channels. Less than $100 \mathrm{ppm}$ of CO were found in the outlet stream at $160{ }^{\circ} \mathrm{C}$ with a WHSV $=180 \mathrm{l} /$ (h gcat) in the case of Pt/Rh [6]. With Pt/Co catalysts a temperature window of 130 to $180{ }^{\circ} \mathrm{C}$ at a WHSV=120 l/ (h gcat) was necessary to achieve the desired CO reduction. A different approach was proposed in our group, using direct hydrothermal synthesis of zeolite layers (instead of a washcoated layer) on stainless steel microchannels, followed by ion exchange using Pt. The removal of CO was achieved at low temperatures, $120^{\circ} \mathrm{C}$ at WHSV=120 l/(h g cat), with a 5.6 \%wt. Pt load on the zeolite [8].

While carbon nanotubes have been employed in the SELOX reaction as support of noble metals in fixed bed reactors packed with powdered catalysts (e.g. Pt-Co/CNTs [9], Ni-MgO-Pt/CNTs [10], Pt-Na/CNTs [11] and Ru-CNTs [12]), their use in microreactors for this process has not been reported, which can be probably attributed to the inherent difficulties in achieving a homogeneous and reproducible coating on the microchannels. The work of Thakur et al. [13] is helpful to picture the complexities involved in the preparation of a carbon nanofiber layer as catalyst support in microreactors. These authors used Ru/CNFs on the channels of a silicon microreactor for the catalytic reduction of bromate contaminants in aqueous phase. A number of steps were re- 
quired for the synthesis of the carbon nanofibers (CNFs) layer: First, thin films of nickel/tantalum $(25 \mathrm{~nm} / 10 \mathrm{~nm})$ were deposited on the oxidized silicon substrates using electron-beam evaporation. This was followed by a controlled reduction step at $650^{\circ} \mathrm{C}$ that produced $\mathrm{Ni}$ nanoparticles, and then the gas mixture containing the carbon source $\left(\mathrm{C}_{2} \mathrm{H}_{4}\right)$ was fed to generate the CNF layer. The ruthenium nanoparticles deposition was accomplished by one of two methods, namely homogeneous deposition precipitation (HDP) and pulsed laser deposition (PLD). HDP used an aqueous solution of ruthenium nitrosyl nitrate and urea which decomposed producing $\mathrm{OH}$ - that locally hydrolyzed the metal salt which then precipitated as a hydroxide. Further calcination and reduction steps were needed. Furthermore, to achieve a good anchoring of the Ru nanoparticles the CNFs had to be previously oxidized, and the $\mathrm{pH}$ had to be carefully controlled during the precipitation process. All of these requirements make the method inherently complex and difficult to apply for production at a larger scale.

In this work we present a general, scalable method, to prepare a catalytic coating on the surface of stainless steel microchannels. This method comprises three steps: first, the catalytic support (a layer of randomly oriented CNFs) is directly grown on the surface of the channels by chemical vapor deposition (CVD) of ethanol, second, the surface of the CNFs was modified to achieve a positive charge by a simple contact procedure (a poly-ethylenimine solution was pumped through the microchannels) and finally a solution containing preformed metallic Pt nanoparticles was flown through the channels to obtain highly dispersed Pt nanoparticles on the CNFs. The catalytic plates prepared using this method have been tested in the preferential oxidation of $\mathrm{CO}$ and their activity was compared to a very similar catalyst (i.e. the same Pt on commercial CNFs) as a powder in a conventional fixed bed reactor configuration.

\section{Material and methods}

\subsection{Chemicals}

Tetrakis (hydroxymethyl) phosphonium chloride solution (THPC, 80 wt. \% Aldrich), poly(vinyl pyrrolidone) (PVP, MW \# 10000 Da, Aldrich), chloroplatinic acid 8 wt. \% solution $\left(\mathrm{HPtClO}_{4}\right.$, Aldrich), sodium hydroxide ( $\mathrm{NaOH}$, Aldrich), nitric acid ( $\mathrm{HNO}_{3}, 70 \%$ Aldrich), Polyethylenimine (PEI, branched, Aldrich), and CNTs (Baytubes C150P, Bayern) were all used as received. 


\subsection{Preparation of catalytic microreactors}

The microreactors consist of stainless steel (AISI 316) plates (80 mm x $20 \mathrm{~mm} \times 2 \mathrm{~mm}$ ) containing 12 semicircular microchannels (length $=50 \mathrm{~mm}$, diameter $=500 \mu \mathrm{m}$ ). The plates were designed by us and manufactured using chemical etching by Exella (Exella Europe SRLwww.exella.es). The growth of the carbon nanofiber layer on the microchannels was performed by CVD of ethanol. The plates to be covered were placed in a quartz tube inside a horizontal furnace with a total length $30 \mathrm{~cm}$. The temperature profile along the tube was measured to ensure that a central isothermal section of at least $12 \mathrm{~cm}$ length existed, and therefore could be used to host the plates under a homogeneous temperature. The microreactor was heated up to $750{ }^{\circ} \mathrm{C}$ with a heating rate of $40{ }^{\circ} \mathrm{C} / \mathrm{min}$, under an equimolar flow of $\mathrm{H}_{2} / \mathrm{N}_{2}\left(\mathrm{Q}_{\mathrm{T}}=400 \mathrm{~mL} / \mathrm{min}\right)$. This flow was maintained for 60 minutes. Finally, $10 \mathrm{~g} / \mathrm{h}$ of ethanol and $400 \mathrm{~mL} / \mathrm{min}$ of $\mathrm{N}_{2}$ were introduced, at atmospheric pressure, for 60 minutes.

The synthesis of the Pt nanoparticles followed previously reported methods in our laboratory [14], based on the use of tetrakis-(hydroxymethyl)-phosphonium chloride, THPC, as both reducing and capping agent, controlling the kinetics of the nucleation-crystallization process in order to achieve a monodisperse distribution of ultra-small Pt nanoparticles under the size of $1.5 \mathrm{~nm}$. In a typical synthesis, $100 \mu \mathrm{L}$ of $\mathrm{H}_{2} \mathrm{PtCl}_{6}$ in $\mathrm{H}_{2} \mathrm{O}$ (8 \%wt.) were added to $15 \mathrm{~mL}$ of $\mathrm{H}_{2} \mathrm{O}$. Then, $333 \mu \mathrm{L}$ of THPC $65 \mathrm{mM}$ in $\mathrm{H}_{2} \mathrm{O}$ and $165 \mu \mathrm{L}$ of $\mathrm{NaOH} 1 \mathrm{M}$ in $\mathrm{H}_{2} \mathrm{O}$ were added. The mixture was covered with foil and stirred at 300 rpm for 4 days at room temperature. To estimate the synthesis yield, the solution was destabilized by addition of HNO3 to lower the $\mathrm{pH}$ to 3 . Under these conditions the colloidal solution is not stable and the nanoparticles precipitate to the bottom. The Pt content of the supernatant liquid was then analyzed using Microwave Plasma-Atomic Emission Spectroscopy, MP-AES (Agilent 4100-MP-AES).

The anchoring of the Pt nanoparticles to the CNFs grown on the channels is based on electrostatic interactions, and was carried out in situ under continuous flow using the same microreactor employed for reaction. The CNFs surface was modified with a positively charge polymer, Polyethylenimine (PEI) to promote the electrostatic interaction with the negatively charged Pt nanoparticles. First, a $10 \mathrm{~mL}$ solution of PEI in $\mathrm{H}_{2} \mathrm{O}(4 \mathrm{~g} / \mathrm{L})$ was pumped (Harvard PHD Ultra) through the channels of the microreactor (Figure 1.a). Then, $250 \mu \mathrm{L}$ of the Pt solution $(0.23 \mathrm{mg}$ $\mathrm{Pt} / \mu \mathrm{l}$ ) were fed into the channels at a flow rate of $1 \mathrm{~mL} / \mathrm{min}$. The outlet solution, after passing through the microreactor, was clear compared to the initial dark solution. The Pt content of the inlet and outlet solution was analyzed using MP-AES. 
For comparison, a similar catalyst in a powdered (unsupported) form was prepared from commercial CNTs with two different Pt loadings following the procedure previously described by Zhou et al. [15]. Briefly, $100 \mathrm{mg}$ of CNTs (Baytubes C150P) were sonicated in $15 \mathrm{~mL}$ of $\mathrm{H}_{2} \mathrm{O}$ for

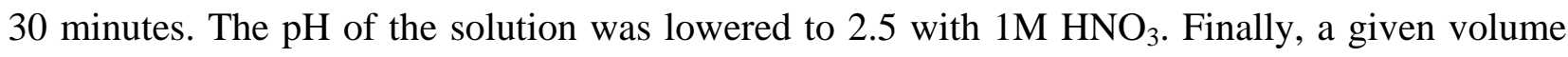
(15 mL and $30 \mathrm{~mL}$ ) of the Pt solution containing nanoparticles was added to the CNTs at a flow rate of $1 \mathrm{~mL} / \mathrm{min}$ while the mixture was kept under sonication. Then, the powder was vacuum filtered and dried at $100{ }^{\circ} \mathrm{C}$ for $12 \mathrm{~h}$.

\subsection{Characterization of the catalysts}

The morphology of the catalysts was characterized, before and after the activity tests by scanning electron microscopy, SEM (FEI Inspect S50), and transmission electron microscopy, TEM (FEI Tecnai T20 at $200 \mathrm{kV}$ ) at the Laboratory of Advanced Microscopies, LMA, University of Zaragoza.

The loading of Pt catalysts was determined by MP-AES after digestion of the solid samples. Complete digestion of the powder samples was achieved using aqua regia in a ratio $1 \mathrm{mg}$ catalyst: $1 \mathrm{~mL}$ aqua regia, during 24 hours at room temperature. Since the stainless steel was also dissolved in the case of the microreactors, the layer of CNFs was first detached, immersing the plates in water followed by sonication for 60 minutes. After that time it was possible to observe that the entire layer was detached.

\subsection{Catalytic activity test}

The SELOX reaction was carried out at atmospheric pressure using a feed stream with a composition of $97.4 \% \mathrm{H}_{2}, 1.28 \% \mathrm{CO}$ and $1.28 \% \mathrm{O}_{2}$, corresponding to $\lambda=2$ (double of the stoichiometric $\mathrm{O}_{2}$ necessary to fully oxidize the $\mathrm{CO}$ in the feed). The total flow rate was $10 \mathrm{ml} / \mathrm{min}$ for the microreactors and $100 \mathrm{~mL} / \mathrm{min}$ for the unsupported CNTs catalyst, giving WHSV values from 2220 to 13320 [l/ h g $\mathrm{gt}_{\mathrm{Pt}}$ depending on the Pt loading of the catalyst. The reaction temperature was increased from 50 to $250{ }^{\circ} \mathrm{C}$ in steps of $25^{\circ} \mathrm{C}$. Prior to the catalytic testing, an oxidation (Air, 10 $\mathrm{ml} / \mathrm{min}$ for $60 \mathrm{~min})$ and reduction $\left(50 \% \mathrm{H}_{2}, 50 \% \mathrm{~N}_{2}, 10 \mathrm{ml} / \mathrm{min}\right.$ for $\left.30 \mathrm{~min}\right)$ treatment was conducted at $250{ }^{\circ} \mathrm{C}$. The activity tests in the microreactors were carried out with one, three, and six plates arranged in parallel (see scheme in Figure 1). The microreactors were placed in an aluminum housing block to provide thermal inertia. The temperature was regulated by four electrical resistances (Figure 1) controlled by a thermocouple located in the middle of the block. Reaction experiments on CNTs catalyst in powder form were carried out in a conventional fixed bed reactor $(100 \mathrm{mg}$ catalyst, bed height $=1 \mathrm{~cm}$, diameter $=6 \mathrm{~mm})$. 
The composition of the exit gases was analyzed by an on-line gas chromatograph (Varian MicroGC-4900) equipped with thermal conductivity detectors and two columns, CP740148 MS5A and CP740150 PPQ, for the analysis of permanent gases $\left(\mathrm{H}_{2}, \mathrm{O}_{2}\right.$ and $\left.\mathrm{CO}\right)$ and $\mathrm{H}_{2} \mathrm{O}$ and $\mathrm{CO}_{2}$, respectively. The detection limit for CO was 5 ppm. The CO conversion and selectivity were calculated according to the following expressions:

$$
\begin{aligned}
& \text { Conversion }=\frac{\mathrm{CO}_{\text {in }}-\mathrm{CO}_{\text {out }}}{\mathrm{CO}_{\text {in }}} \times 100 \\
& \text { Selectivity }=0.5 \times \frac{\mathrm{CO}_{\text {in }}-\mathrm{CO}_{\text {out }}}{\mathrm{O}_{2_{\text {in }}}-\mathrm{O}_{2_{\text {out }}}} \times 100
\end{aligned}
$$

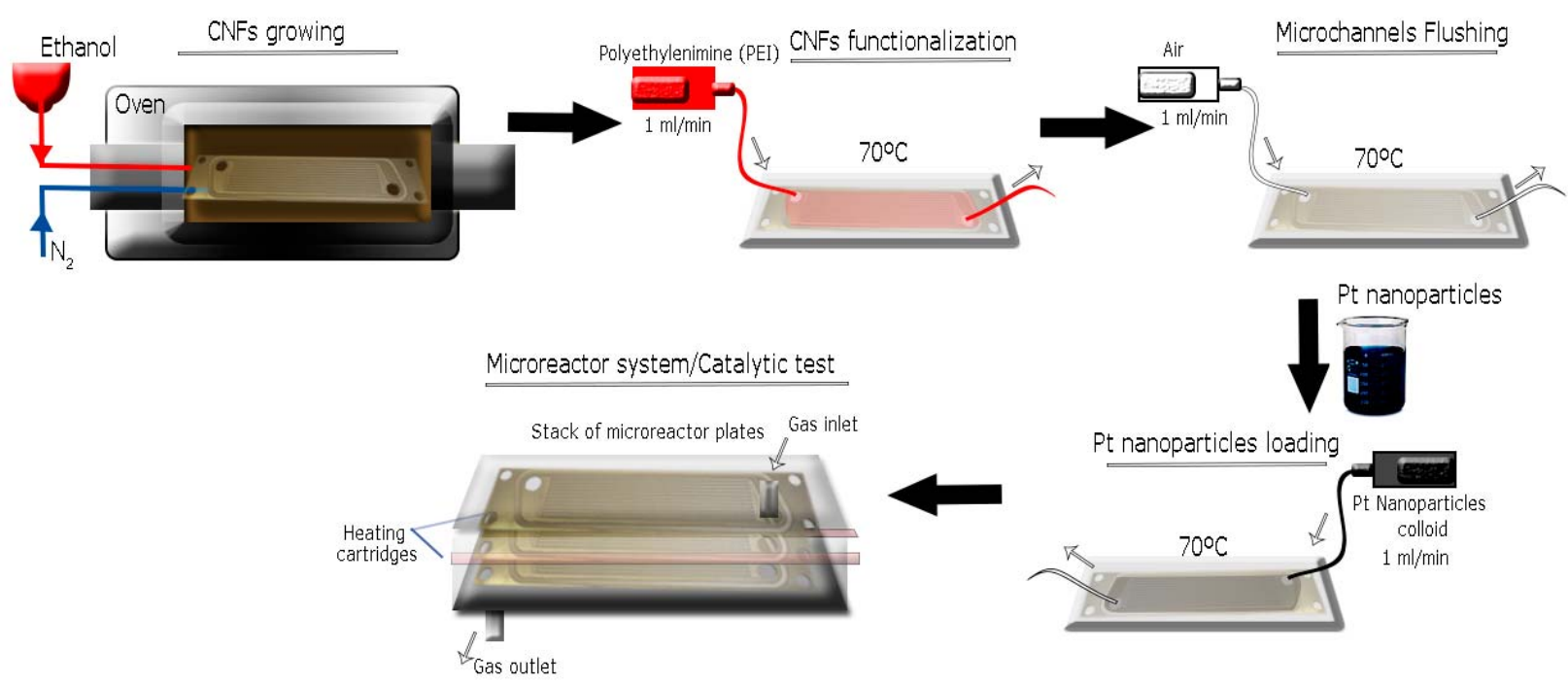

Figure 1. Pt nanoparticles deposition scheme and microreactor assembly.

\section{Results and discussion}

\subsection{Characterization of the catalysts}

The CNF layer grown by CVD uses the Fe in the stainless steel as catalysts [16, 17], avoiding the initial catalyst deposition step. CNF growth in this work was performed in separate experiments in a total of 20 plates. The results show that, under optimal conditions (see below) in all the cases the CNFs layer was located exclusively inside the channels, while growth of CNFs on the channel interspaces was avoided. This could be observed just by visual inspection (see Figure 2a) and was corroborated on a closer inspection using microscopy. Optimal growth was achieved at a CVD temperature of $750{ }^{\circ} \mathrm{C}$. Higher temperatures led to uncontrolled growth throughout the microreactor, while at significantly lower temperatures the growth did not occur. The preferential growth of CNFs in the channel space at $750{ }^{\circ} \mathrm{C}$ can be explained as a consequence of the acid 
etching performed on the channels during preparation. This activated the surface and gave rise to a higher roughness of the metallic surface in the channel, allowing the preferential formation of CNFs at lower temperatures. After CVD the average weight of the CNFs per microreactor plate was $10 \pm 1.26 \mathrm{mg}$, indicating a high reproducibility of the procedure.
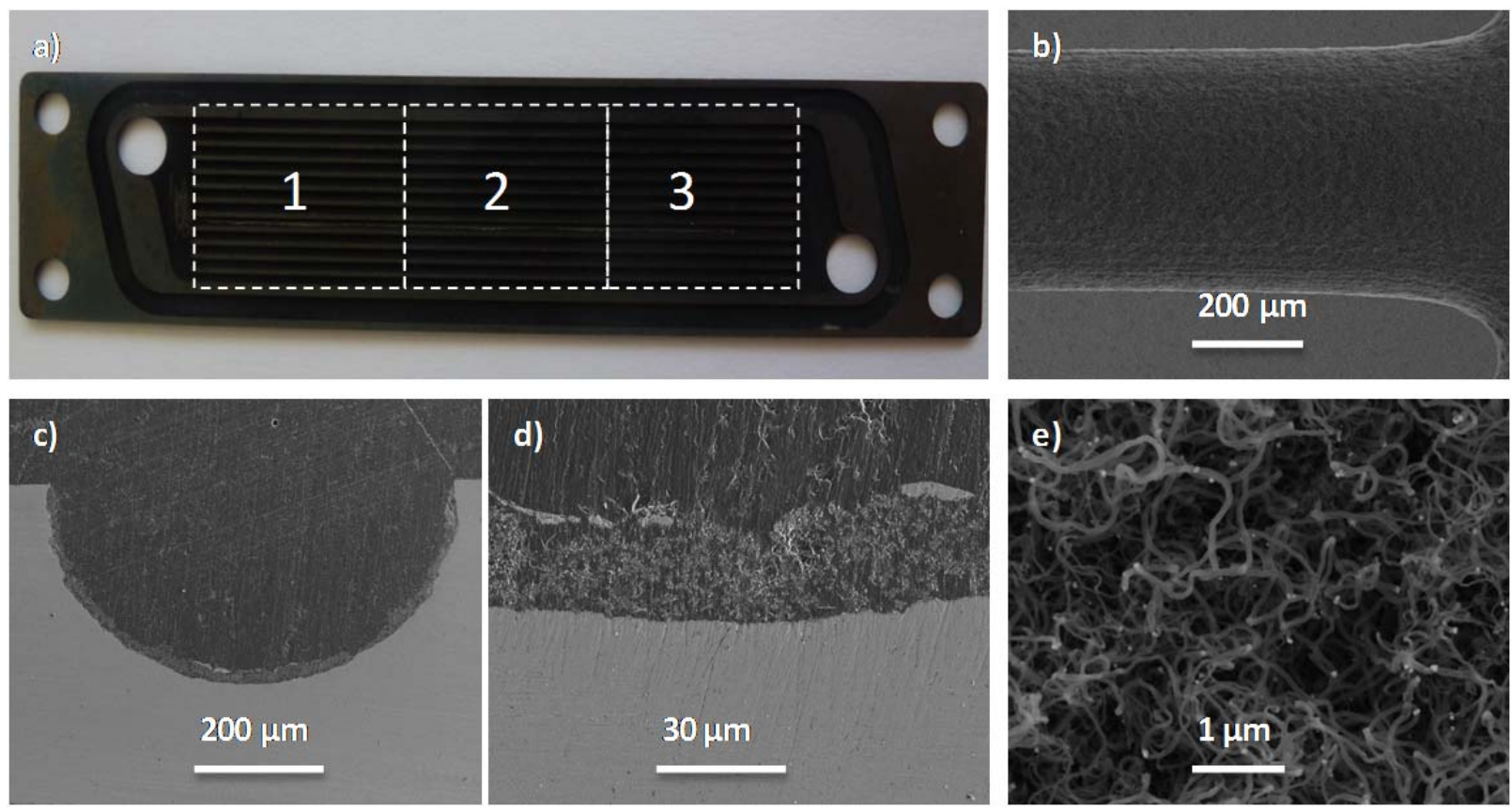

Figure 2. a) Image of the catalytic microreactor, showing the division in 3 sections used for chemical analysis b) SEM image top view of the channel c, d) SEM images of channel cross section at different magnifications, showing the CNFs layer (thickness = 20 microns) e) SEM image detailed top view of the CNFs grown on the microreactor channel.

The SEM images of the microreactor channel top view and cross sections, Figure $2 \mathrm{~b}$ and 2c, again confirm that the nanotubes were grown exclusively on the surface of the channels and not on the flat surfaces between channels. This is important since a clean interlayer surface is essential for a good sealing of the plates. Growth was homogeneous in all the semicircular section, compared to the traditional washcoating method that in some cases gives rise to nonhomogeneous Vshaped coatings [18]. The layer consists of a carbon nanofibers bush, with high porosity and a height of c.a. $20 \mu \mathrm{m}$ (Figure 2c). The carbon layer consists mainly of CNFs, with an average diameter of $72 \pm 15.4 \mathrm{~nm}$ (measured by TEM).

As already explained in the experimental section, the deposition of the Pt nanoparticles on the CNFs was done using a continuous process based on electrostatic interactions (see Figure 3d), using PEI as cationic polymer. This process was previously used to functionalize individual carbon nanotubes with gold nanoparticles [19] but here it is applied for the first time to deposit nanoparticles on a supported CNF bush, where it is more difficult to guarantee a homogeneous contact of the CNFs first with the cationic polymer and then with the nanoparticle suspension. However, 
as shown below, the in situ procedure used in this work provides an easy way to decorate the CNF bush with ultra-small Pt nanoparticles, since both the cationic polymer and the Pt colloid solutions are sequentially flown through the channels, providing an intimate contact with the supported CNFs.

To study the distribution of the Pt nanoparticles, after deposition the CNFs were detached from the plates by sonication and observed by TEM. An image of the nanoparticles in the suspension used for decoration is shown in figure 3a, together with the particle size distribution (see inset), centered at $1.7 \pm 0.2 \mathrm{~nm}$. Figure $3 \mathrm{~b}$ and 3c present arepresentative image of the Pt-decorated nanofibers. It can be seen that the Pt nanoparticles are well distributed throughout the surface of the CNFs and additional agglomeration upon deposition is largely avoided. Thus, the method of deposition of the Pt nanoparticles is suitable, providing a good dispersion of metal nanoparticles on the CNFs grown in the channel.
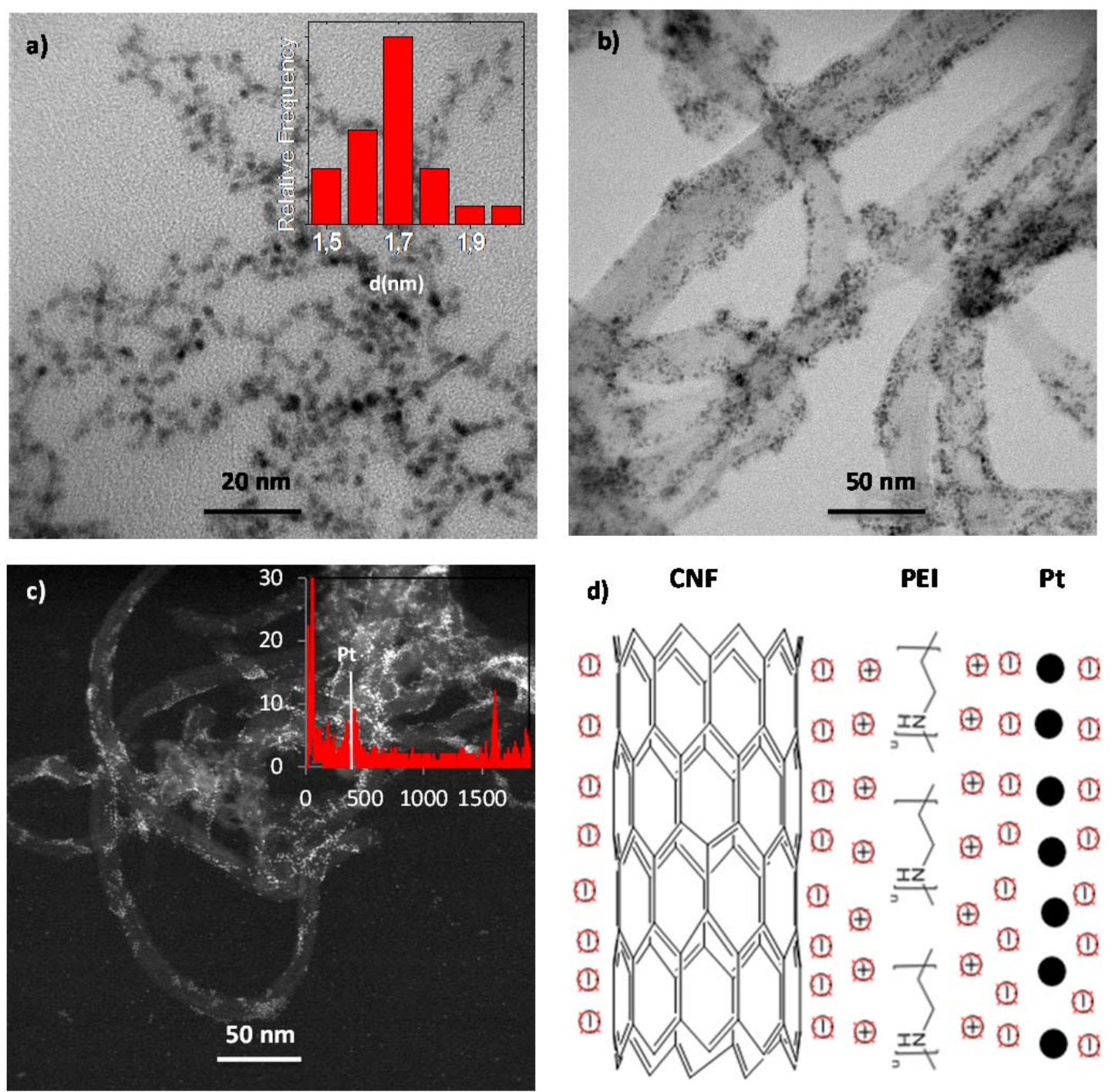
Figure 3. a) TEM image of the Pt nanoparticles, inset histogram nanoparticle diameter, b) TEM image of the $\mathrm{Pt} / \mathrm{CNFs}$ microreactor catalyst, b) STEM image of the Pt/CNFs microreactor catalyst (EDX insert), d) Pt/CNFs interaction scheme.

The results concerning Pt loading are presented in Tables 1 and 2. To study the Pt loading and reproducibility and homogeneity of the Pt distribution along the length of the reactor, two reactors (M3 and M4) were opened, cut in three sections (see Figure 2.a), and subjected to chemical analysis by MP-AES after detaching the CNFs using ultrasounds for $60 \mathrm{~min}$. Another two microreactors were analyzed (M1, M2) using the same procedure, but without cutting them in three sections. To check the validity of this method, the average loading of Pt nanoparticles in the reactor (M1 and M2) was estimated also non-destructively by the difference on the concentration of the inlet and outlet Pt solutions.

The results in Table 1 show that the procedure used yields reproducible samples with a homogeneous Pt load along the reactor channels, around 0.45 \%Pt. However, the calculations based on the concentration of the inlet and outlet solutions (see Table 2) show less Pt loading due to the deposition of same Pt nanoparticles in the holder and the sealing during the deposition step. The Pt content in the CNT powders was also measured giving loads of $2.81 \pm 0.19$ and $5.7 \pm 0.31 \mathrm{wt}$. \% in each of the two samples prepared.

Table 1. Pt load in microreactors. Determination based on MPAES analysis of detached CNFs after sonication.

\begin{tabular}{|c|c|c|c|c|}
\hline \multicolumn{2}{|c|}{ Sample } & $\begin{array}{c}\mathbf{m}_{\mathrm{CNFs}} \\
(\mathrm{mg})\end{array}$ & \multicolumn{2}{|c|}{$\begin{array}{c}\% \mathrm{Pt} \pm \mathrm{RSD} \% \\
\text { in CNFs in microreator }\end{array}$} \\
\hline \multicolumn{2}{|c|}{ M1 } & 10.56 & \multicolumn{2}{|c|}{$0.45 \pm 3.64 \%$} \\
\hline \multicolumn{2}{|c|}{ M2 } & 9.67 & \multicolumn{2}{|c|}{$0.47 \pm 0.89 \%$} \\
\hline M3.1 & \multirow{3}{*}{ M3 $3_{\text {average }}$} & 3.59 & $0.55 \pm 3.33 \%$ & \multirow{3}{*}{0.47} \\
\hline M3.2 & & 3.59 & $0.49 \pm 0.97 \%$ & \\
\hline M3.3 & & 3.59 & $0.39 \pm 3.03 \%$ & \\
\hline M4.1 & \multirow{3}{*}{ M4 $4_{\text {average }}$} & 3.26 & $0.46 \pm 2.84 \%$ & \multirow{3}{*}{0.43} \\
\hline M4.2 & & 3.26 & $0.39 \pm 3.03 \%$ & \\
\hline M4.3 & & 3.26 & $0.43 \pm 2.14 \%$ & \\
\hline
\end{tabular}

NOTE: To calculate the load for each section it has been assumed that the CNF growth is homogeneous and each section accounts for one third of the total CNF mass. 
Table 2. Pt load in microreactors. Determination based on the difference between the inlet and outlet Pt concentration in the solution used for NP deposition in microchannels.

\begin{tabular}{|c|c|c|c|c|c|}
\hline Sample & $\begin{array}{c}\mathbf{m}_{\text {CNFs }} \\
\mathbf{( m g )}\end{array}$ & $\begin{array}{c}{[\mathbf{P t}]_{\text {inlet solution }}} \\
\mathbf{p p m}\end{array}$ & $\begin{array}{c}{[\mathbf{P t}]_{\text {outlet solution }}} \\
\mathbf{p p m}\end{array}$ & $\begin{array}{c}\text { Pt in microreac- } \\
\text { tor (mg) }\end{array}$ & $\begin{array}{c}\text { Pt \% wt. in } \\
\text { CNFs in micro- } \\
\text { reator }\end{array}$ \\
\hline M1 & 10.56 & $229 \pm 1.17 \%$ & $71 \pm 0.78 \%$ & 0.0395 & 0.375 \\
\hline M2 & 9.67 & $229 \pm 1.17 \%$ & $72 \pm 0.64 \%$ & 0.0393 & 0.406 \\
\hline
\end{tabular}

\subsection{Activity tests SELOX reaction fixed bed and catalytic bed}

The conversions of $\mathrm{CO}$ and $\mathrm{O}_{2}$ together with $\mathrm{CO}_{2}$ selectivity are presented in Figure 4 for the three different space velocities in the microreactors, containing 1, 3 and 6 plates with an average of $0.45 \%$ wt. Pt. It is necessary to use 6 plates, i.e. WHSV=9.6 l/h g, to completely remove carbon monoxide in the reformate stream (100\% CO conversion, CO concentration below detection limit of GC $5 \mathrm{ppm}$ ), and this is achieved at a relatively low temperature $175^{\circ} \mathrm{C}$. This temperature is in the same range as the best results reported using microreactors for SELOX using more active bimetallic catalysts [6, 7], (see introduction section).

The upper limit of the temperature window for total CO conversion is around $200{ }^{\circ} \mathrm{C}$. Above this temperature the selectivity decreases and a larger proportion of oxygen is consumed in the oxidation of hydrogen to water, causing a decrease in CO conversion. This temperature window could be broadened by increasing the amount of oxygen, as shown by Galetti et al. [20] using a microchannel coated with a Rh catalyst (0.5 wt.\%) supported on mixed system $50 \% \gamma-\mathrm{Al}_{2} \mathrm{O}_{3} 50 \%$ $3 \mathrm{~A}$-zeolite. The temperature window for total CO conversion broadened from $158-162^{\circ} \mathrm{C}$ to 140 $200^{\circ} \mathrm{C}$ when $\lambda$ increased from 2 to 3 . 


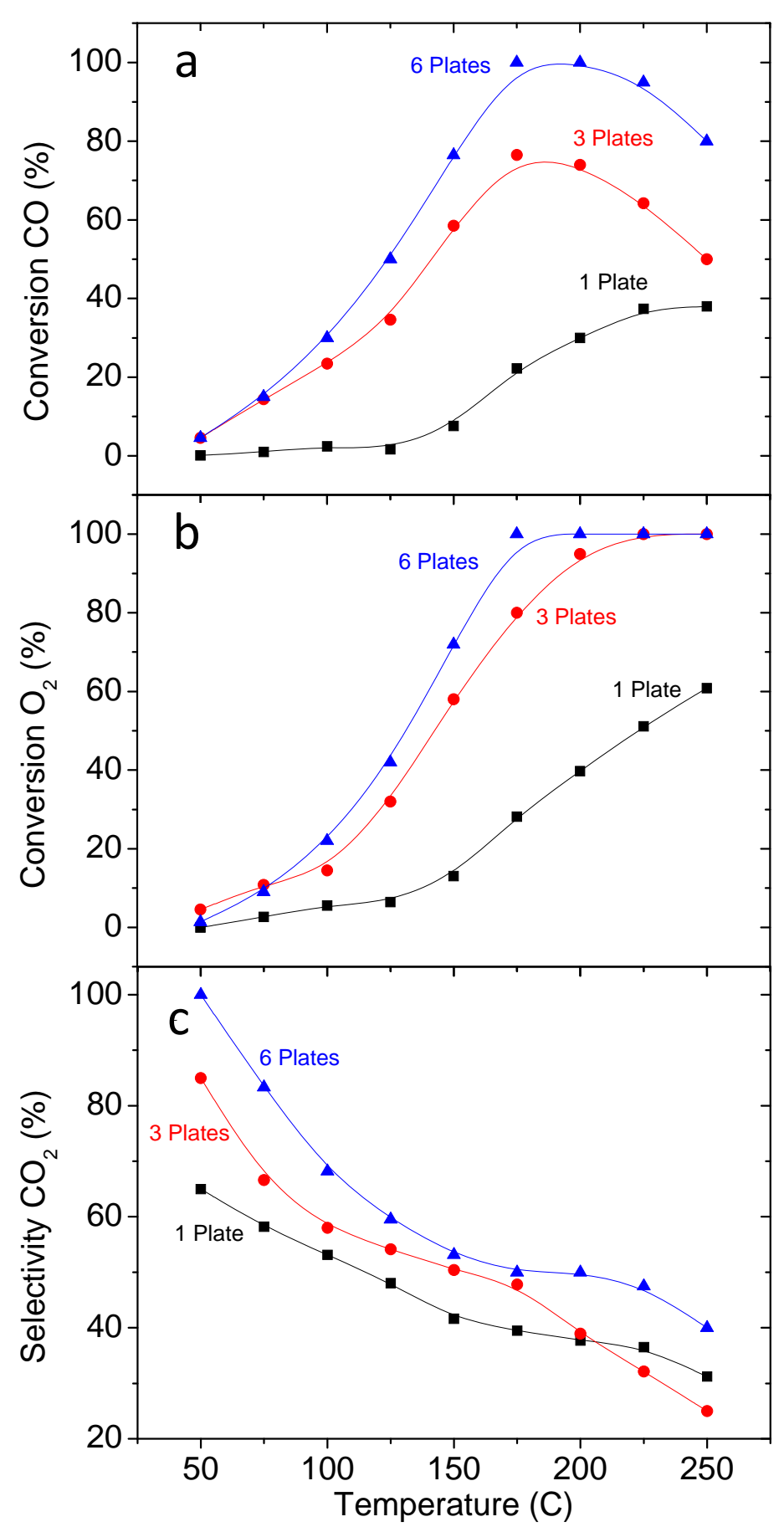

Figure 4. Catalytic behavior of the microreactor system (1, 3 and 6 plates) for the SELOX reaction. Flow rate $10 \mathrm{~mL} / \mathrm{min}$, Feed composition: $97.4 \% \mathrm{H}_{2}, 1.28 \% \mathrm{CO}$ and $1.28 \% \mathrm{O}_{2}$,: a) Conversion of $\mathrm{CO}$ as a function of temperature, b) $\mathrm{O}_{2}$ conversion as a function of temperature, c) Selectivity to $\mathrm{CO}_{2}$ as a function of temperature.

The catalytic behavior of the powder catalyst vs. the microreactor, for the same value of space velocity, based on noble metal load (WHSV $=2220 \mathrm{l} / \mathrm{h} \mathrm{g}_{\mathrm{Pt}}$ ), is presented in Figure 5. The microreactor clearly outperformed the fixed bed reactor, as observed previously in other catalytic systems [8]. In this case we believe that a higher accessibility to the catalytic nanoparticles, deposited in the open structure of the CNF bush together with shorter diffusion lengths, is responsible for the higher conversions observed at the same temperature. This also true for different space velocities, 
see Figure 5b. Finally, the stability of the catalyst in the microreactor integrated by six plates was tested for sixty hours. The results are presented in Figure 5.c and show stable values for conversion and selectivity.
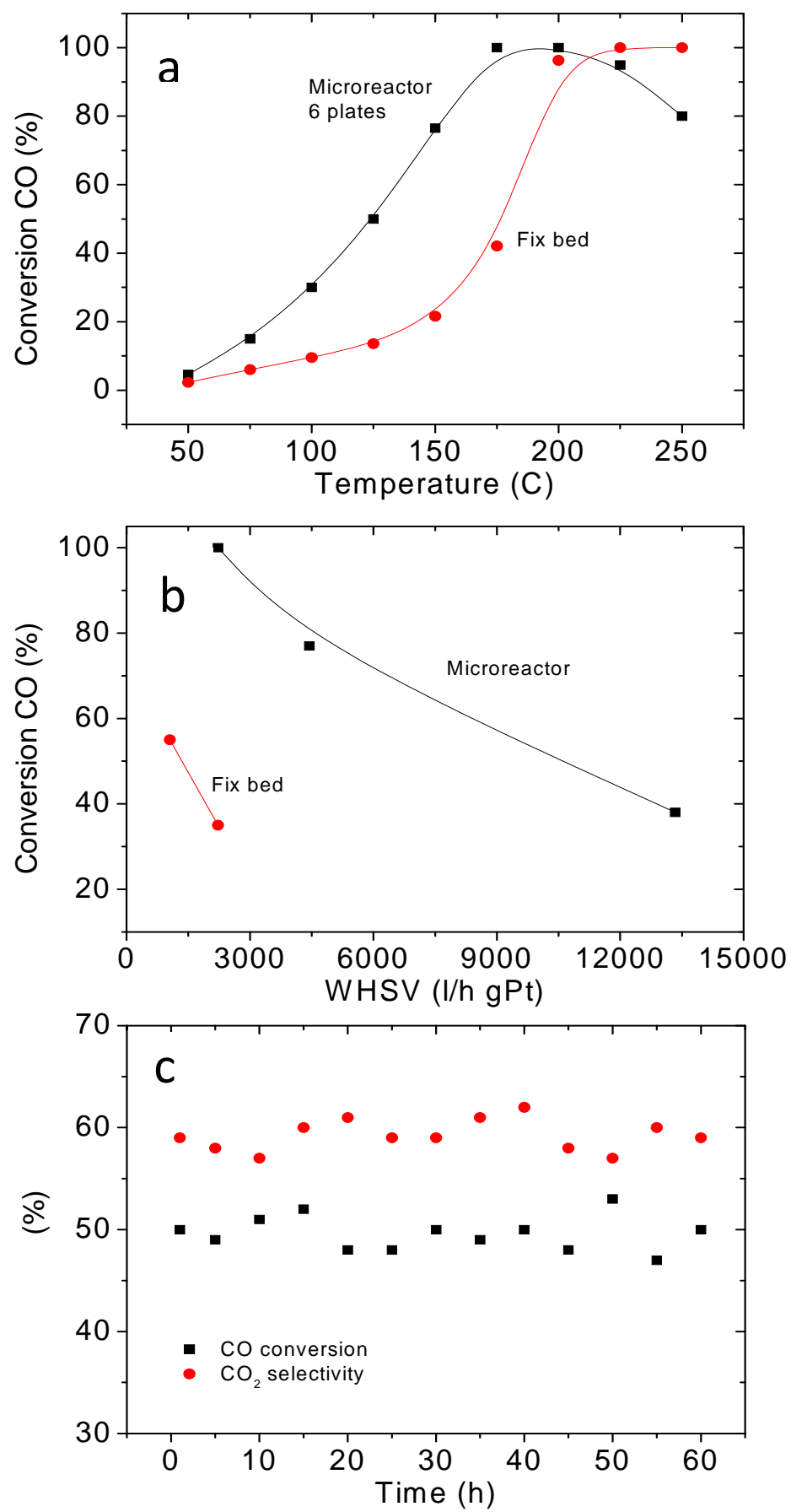

Figure 5. a) Conversion of $\mathrm{CO}$ as a function of temperature, WHSV=2220 (l/h gPt), 6 microreactor plates $(0.45 \%$ wt. $\mathrm{Pt}$ ) and fixed bed reactor (2.7\%wt. Pt) b) Conversion of $\mathrm{CO}$ versus space time at $\mathrm{T}=175^{\circ} \mathrm{C}$ for microreactors and fixed bed. c) Stability of the six parallel microreactors system at $125^{\circ} \mathrm{C}$, conversion of $\mathrm{CO}$ and selectivity of $\mathrm{CO}_{2}$ vs. time.

A comparison between our system and imilar catalyst based on Pt supported on CNTs, tested in fixed bed configuration is shown in Table 3 . The temperatures to achieve $100 \%$ conversion of CO 
over unpromoted catalyst lie in the same range, considering the space velocity based on the total amount of metal. The catalyst promoted with Na show better performance compared to our results.

Table 3. Comparison between literature data of Pt catalyst supported on CNTs in fixed bed reactors and our work.

\begin{tabular}{|c|c|c|c|c|}
\hline Catalyst & $\begin{array}{c}\text { Temp. } \\
{[\mathbf{K}]}\end{array}$ & $\begin{array}{c}\text { Conv. } \\
\text { CO }\end{array}$ & $\begin{array}{c}\text { WSHV } \\
{\left[\mathbf{l} / \mathbf{g}_{\text {metal }} \mathbf{h}\right]}\end{array}$ & Ref. \\
\hline $4 \%$ Pt-CNTs & 450 & 100 & 600 & {$[9]$} \\
\hline $4 \%$ Pt/1\%Co-CNTs & 390 & 100 & 600 & {$[9]$} \\
\hline $5 \%$ Pt/5\%Ni/5\%Mg-CNTs & 350 & 100 & 210 & {$[10]$} \\
\hline $5 \%$ Pt/Na-CNTs & 313 & 100 & 4200 & {$[11]$} \\
\hline Fixed bed 2,7\%Pt-CNFs & 498 & 100 & 2200 & This work \\
\hline 6 MRPlates 0.45\%Pt-CNFs & 448 & 100 & 2200 & This work \\
\hline
\end{tabular}

The distribution of the nanoparticles in the commercial nanotubes (used for the fixed bed experiments) and in the microreactors grown CNFs, was examined after 60 hours of reaction (see Figure 6). It can be observed that the nanoparticle size undergoes similar increases in both cases, from $1.7 \pm 0.2$ (see Figure 3b) to roughly $5 \pm 0.8 \mathrm{~nm}$ in both cases. In spite of this increase, as we have already seen, the catalyst activity is maintained for at least $60 \mathrm{~h}$ on stream.
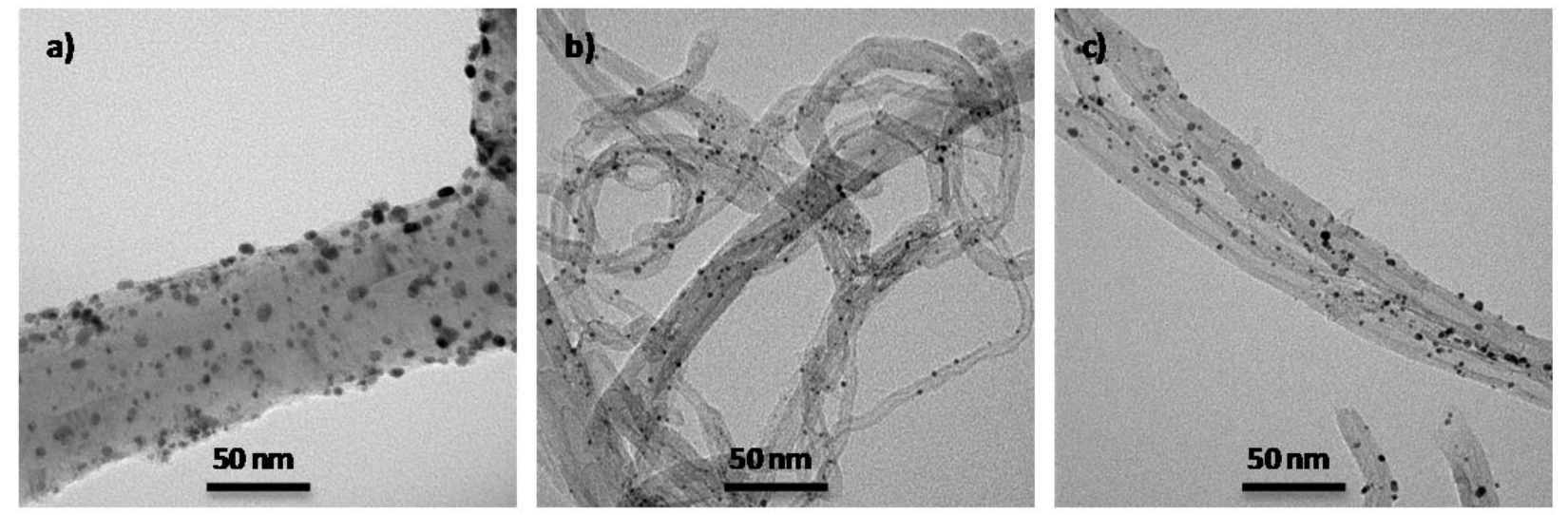

Figure 6. TEM images of catalyst after $10 \mathrm{~h}$ in stream: a) Pt/CNFs Microreactor; b) 2.8 \% Pt/CNTs Fixed bed; c) 5.7 $\% \mathrm{Pt} / \mathrm{CNTs}$ Fixed bed.

\section{Conclusions}

The novel in situ method presented in this work allows the preparation of highly accessible Pt catalyst on a carbon nanofiber support directly grown on the channels of a stainless steel microreactor. The protocol is effective in controlling the selective growth of the CNFs bush in the micro- 
reactor channels exclusively. The method to attach the Pt catalyst nanoparticles to the CNFs by a continuous flow of the nanoparticle suspension produces a highly dispersed, homogeneous Pt distribution on the carbon nanofibers. These microreactors clearly outperform the fixed bed reactor packed with Pt/CNTs, for the same value of space velocity, obtaining $100 \%$ CO conversion at temperatures $50^{\circ} \mathrm{C}$ lower.

\section{Acknowledgments}

Authors acknowledge the financial support of the DGA-La Caixa (Grant: 2012/GA LC 086). People Program (Marie Curie Actions) of the EU under the REA grant agreement no. 321642 is also gratefully acknowledged

\section{References}

[1] G. Kolb, Review: Microstructured reactors for distributed and renewable production of fuels and electrical energy, Chemical Engineering and Processing: Process Intensification, 65 (2013) 1-44.

[2] R. Zapf, G. Kolb, H. Pennemann, V. Hessel, Basic study of adhesion of several alumina-based washcoats deposited on stainless steel microchannels, Chemical Engineering and Technology, 29 (2006) 1509-1512.

[3] R. Zapf, C. Becker-Willinger, K. Berresheim, H. Bolz, H. Gnaser, V. Hessel, G. Kolb, P. Löb, A.K. Pannwitt, A. Ziogas, Detailed characterization of various porous alumina-based catalyst coatings within microchannels and their testing for methanol steam reforming, Chemical Engineering Research and Design, 81 (2003) 721-729.

[4] V. Meille, Review on methods to deposit catalysts on structured surfaces, Applied Catalysis A: General, 315 (2006) 1-17.

[5] G.A. Kovalenko, O.V. Komova, A.V. Simakov, V.V. Khomov, N.A. Rudina, Macrostructured carbonized ceramics as adsorbents for immobilization of glucoamylase, Journal of Molecular Catalysis A: Chemical, 182-183 (2002) 73-80.

[6] V. Cominos, V. Hessel, C. Hofmann, G. Kolb, R. Zapf, A. Ziogas, E.R. Delsman, J.C. Schouten, Selective oxidation of carbon monoxide in a hydrogen-rich fuel cell feed using a catalyst coated microstructured reactor, Catalysis Today, 110 (2005) 140-153.

[7] H. Li, X. Yu, S.T. Tu, J. Yan, Z. Wang, Catalytic performance and characterization of Al2O3-supported PtCo catalyst coatings for preferential CO oxidation in a micro-reactor, Applied Catalysis A: General, 387 (2010) 215-223.

[8] V. Sebastian, S. Irusta, R. Mallada, J. Santamaría, Microreactors with Pt/zeolite catalytic films for the selective oxidation of CO in simulated reformer streams, Catalysis Today, 147 (2009) S10-S16.

[9] C. Wang, B. Li, H. Lin, Y. Yuan, Carbon nanotube-supported Pt-Co bimetallic catalysts for preferential oxidation of $\mathrm{CO}$ in a H2-rich stream with $\mathrm{CO} 2$ and H2O vapor, Journal of Power Sources, 202 (2012) 200208.

[10] H. Yang, C. Wang, B. Li, H. Lin, K.-i. Tanaka, Y. Yuan, Doping effects of Ni-MgO on the structure and performance of carbon nanotube-supported Pt catalysts for preferential oxidation of $\mathrm{CO}$ in a $\mathrm{H} 2$ stream, Applied Catalysis A: General, 402 (2011) 168-175.

[11] C. Wang, G. Yi, H. Lin, Y. Yuan, Na+-intercalated carbon nanotubes-supported platinum nanoparticles as new highly effective catalysts for preferential $\mathrm{CO}$ oxidation in $\mathrm{H} 2$-rich stream, International Journal of Hydrogen Energy, 37 (2012) 14124-14132.

[12] Y. Gao, K. Xie, S. Mi, N. Liu, W. Wang, W. Huang, Preferential oxidation of CO in a H2-rich stream over multi-walled carbon nanotubes confined Ru catalysts, International Journal of Hydrogen Energy, 38 (2013) 16665-16676. 
[13] D.B. Thakur, R.M. Tiggelaar, T.M.C. Hoang, J.G.E. Gardeniers, L. Lefferts, K. Seshan, Ruthenium catalyst on carbon nanofiber support layers for use in silicon-based structured microreactors, Part I: Preparation and characterization, Applied Catalysis B: Environmental, 102 (2011) 232-242.

[14] J.L. Hueso, V. Sebastián, Á. Mayoral, L. Usón, M. Arruebo, J. Santamaría, Beyond gold: Rediscovering tetrakis-(hydroxymethyl)-phosphonium chloride (THPC) as an effective agent for the synthesis of ultrasmall noble metal nanoparticles and Pt-containing nanoalloys, RSC Advances, 3 (2013) 10427-10433.

[15] Q. Zhou, P. Li, X. Wang, X. Zhou, D. Yang, D. Chen, Preparation of CNF-supported Pt catalysts for hydrogen evolution from decalin, Materials Chemistry and Physics, 126 (2011) 41-45.

[16] R.L. Vander Wal, L.J. Hall, Carbon nanotube synthesis upon stainless steel meshes, Carbon, 41 (2003) 659-672.

[17] B. Kim, H. Chung, K.S. Chu, H.G. Yoon, C.J. Lee, W. Kim, Synthesis of vertically-aligned carbon nanotubes on stainless steel by water-assisted chemical vapor deposition and characterization of their electrochemical properties, Synthetic Metals, 160 (2010) 584-587.

[18] A. Stefanescu, A.C. van Veen, C. Mirodatos, J.C. Beziat, E. Duval-Brunel, Wall coating optimization for microchannel reactors, Catalysis Today, 125 (2007) 16-23.

[19] L. Jiang, L. Gao, Modified carbon nanotubes: an effective way to selective attachment of gold nanoparticles, Carbon, 41 (2003) 2923-2929.

[20] C. Galletti, S. Specchia, G. Saracco, V. Specchia, CO preferential oxidation in H2-rich gas for fuel cell applications: Microchannel reactor performance with Rh-based catalyst, International Journal of Hydrogen Energy, 33 (2008) 3045-3048. 